\title{
Effect of Atmospheric Pressure Plasma Treatment Condition on Adhesion of Ramie Fibers to Polypropylene for \\ Composite
}

Ying $\operatorname{Li}^{\mathrm{a}, \mathrm{b}, \mathrm{c}}$, Sorin Manolache ${ }^{\mathrm{b}, \mathrm{d}}$, Yiping Qiu ${ }^{\mathrm{e}^{*}}$ and Majid Sarmadi ${ }^{\mathrm{b}, \mathrm{c}, \mathrm{f}^{*}}$

${ }^{a}$ College of Material and Textile Engineering, Jiaxing University, Jiaxing 314033,

China

${ }^{\mathrm{b}}$ Center for Plasma-Aided Manufacturing, Madison, WI 53706

${ }^{\mathrm{c}}$ School of Human Ecology, University of Wisconsin-Madison, WI 53706

${ }^{\mathrm{d}}$ US Forest Products Laboratory, Madison, WI 53726

${ }^{\mathrm{e}}$ College of Textiles, Donghua University, Shanghai 201620, China

${ }^{\mathrm{f}}$ Materials Science Program, University of Wisconsin-Madison, WI 53706

*Corresponding author. Tel: +86 021 67792744; fax: +86 02167792627

Email: ypqiu@dhu.edu.cn

*Corresponding author. Tel: +001 608 2627492; fax: +001 6082655099

Email: majidsar@wisc.edu 


\section{Abstract}

In order to improve the interfacial adhesion between hydrophilic ramie fibers and hydrophobic polypropylene (PP) matrices, ramie fibers are modified by atmospheric pressure dielectric barrier discharge (DBD) plasma with our continuous ethanol flow technique in helium environment. A central composite design of experiments with different plasma processing parameter combinations (treatment current, treatment time and ethanol flow rate) is applied to find the most influential parameter and to obtain the best modification effect. Field emission scanning electron microscope (SEM) shows the roughened surfaces of ramie fibers from the treated groups due to plasma etching effect. Dynamic contact angle analysis (DCAA) demonstrates that the wettability of the treated fibers drastically decreases. Microbond pullout test shows that the interfacial shear strength (IFSS) between treated ramie fibers and PP matrices increases significantly. Residual gas analysis (RGA) confirms the creation of ethyl groups during plasma treatment. This study shows that our continuous ethanol flow technique is effective in the plasma modification process, during which the ethanol flow rate is the most influential parameter but all parameters have simultaneous influence on plasma modification effect of ramie fibers.

Keyword: Dielectric barrier discharge; Response surface; Ramie fibers; Ethanol vapor; Interfacial adhesion 


\section{Introduction}

As a result of increasing concerns in environmental protection and energy saving, vegetable fibers have been considered as potential alternative reinforcement fibers to man-made synthetic fibers in composites. Among these vegetable fibers, ramie fibers, known as "Chinese plant", are abundant in China [1], which have low cost, low density, similar specific strength and modulus compared to those of glass fibers [2]. On the other hand, ramie fibers also have disadvantages such as poor compatibility with hydrophobic polymer matrices [3], which limits its application as reinforcement in composites.

For many years, various chemical methods have been used to modify the composite interface to increase the compatibility between cellulose fibers and polymer matrices [3-10]. Although these methods are more or less effective, the ever more stringent legislation will little by little lead to the substitution of traditional wet-chemical techniques [11]. In recent years, some new energy-efficient techniques have been developed in cellulose modification [12-22], among which atmospheric plasma treatment has attracted much attention as a clean and high-efficient surface modification technology. Compared with low pressure plasma devices, the atmospheric pressure plasma systems do not require complicated and expensive vacuum system and therefore can be operated at low costs [23-25].

From our previous study, ethanol-soaked ramie fibers exhibited hydrophobicity and rougher surfaces after plasma treatment, enhancing interfacial adhesion between the fibers and polypropylene (PP) matrices [26]. Although ethanol pretreatment plus 
plasma treatment have been effective in surface modification of ramie fibers [27], one of the major drawbacks of this technology is the rapid evaporation of ethanol molecules before and during plasma treatment, making the treatment process less reproducible and controllable.

In this paper, a mixture of ethanol vapor and helium gas with controllable composition was used as plasma treatment environment in a sealed dielectric barrier discharge (DBD) installation. A central composite design of experiments with treatment current $(\mathrm{mA})$, treatment time $(\mathrm{min})$ and ethanol flow rate $(\mathrm{sccm})$ as variables was applied to study the joint influence of simultaneous interaction of the experimental parameters on the fiber surface modificaton effect.

The topology, chemical composition and wettability of the ramie fiber surfaces were characterized by field emission scanning electron microscopy (FESEM), X-ray photoelectron spectroscopy (XPS) and dynamic contact angle analysis (DCAA), respectively. The interfacial shear strength (IFSS) between ramie fibers and PP matrices was measured by microbond pullout test. The chemical composition in plasma treatment chamber was investigated by residual gas analysis (RGA).

\section{Experimental}

\subsection{Materials}

Ramie fibers were supplied by Mahua Technology Co., Ltd. (Suzhou, China) in the form of degumming fibers with a tensile modulus of $25 \mathrm{GPa}$. The diameters of the single fibers ranged from 15 to $40 \mu \mathrm{m}$. The PP matrix was provided by Shanghai Great Eastern Garden Chemical Fiber Co. Ltd. (Shanghai, China) in the form of a 
yarn composed of monofilaments with a Young's modulus of $1.75 \mathrm{GPa}$ and a single fiber diameter around $50 \mathrm{um}$. The ethanol with $99.7 \%$ purity was obtained from Sigma-Aldrich Co., (Milwaukee, WI).

\subsection{Sample preparation and plasma treatment}

Before plasma treatment, all ramie fibers were cleaned with acetone and dried in a vacuum oven. Then the fibers were randomly divided into three groups: the control or untreated group containing fibers without any treatment, the DBD treated only group containing fibers only treated with helium (Purity $\geq 99.999 \%$ ) plasma for $5 \mathrm{~min}$, the DBD plus ethanol treated group containing fibers exposed to helium and ethanol plasma. In DBD plus ethanol treated group, preliminary experiments have been used to select the ranges of plasma treatment parameters. 15 treated groups with different combinations of treatment current, treatment time, and ethanol flow rate were selected according to a three-level factorial central composite design in order to evaluate the joint influence of the plasma treatment parameters on the modification effect of ramie fiber surfaces. Other parameters were kept constant in all experiments (electrode gap distance: $20 \mathrm{~mm}$; reactor temperature: $20^{\circ} \mathrm{C}$; total flow rate: $100 \mathrm{sccm}$; resonant frequency: $30 \mathrm{KHz}$ ). Table 1 is the plasma processing parameters of the 15 treated groups. Before each experiment, the plasma chamber was cleaned with ethanol and flushed by helium gas for $10 \mathrm{~min}$. After plasma treatment, the fibers were immediately put into a clean plastic bag to minimize potential contamination.

The fibers were treated using our custom-made atmospheric pressure DBD system (Fig.1) The copper electrodes (1) are covered by $0.5 \mathrm{~mm}$ thin ceramic sheets (2) and 
embedded into acrylic frames (4); the electrode frames and gas inlet/outlet (7) frames are pressed together with plastic studs (8) and nuts (5) and sealed with silicone O-rings (3). Inside the reactor, acrylic thin blades (6) are restricting the flow of gas at inlet and outlet in order to create a "gas blade" for more uniform distribution. Besides helium gas channel, the continuous flow plasma modification system includes a second channel to introduce ethanol vapor into plasma chamber. Compared with conventional modification method, the continuous ethanol flow technique has many advantages: (1) the ethanol volume fraction could be controlled accurately; (2) treatment gas composition is constant during the treatment duration; (3) the fiber surface defects caused by plasma over-etching might be decreased by continuously introducing ethanol in treatment process.

\subsection{SEM analysis}

The surface topology of the fibers was observed using a LEO 1530 Field emission, digital scanning electron microscrope (LEO Electron Microscopy Inc., Thornwood, NY). The magnifications of the image were set at $10000 \times$. The samples were gold sputtered at $50 \mathrm{mTorr}$ and $45 \mathrm{~mA}$ for $30 \mathrm{~s}$ in a Desk II system sputter coater (Denton Vacuum Inc., Moorestown, NJ) before examination to ensure good surface conductivity.

\subsection{Wettability measurements}

The wettability of ramie fibers was determined on a dynamic contact angle analyzer DCA322 (Thermo Cahn Instruments, WI) according to Wihelmy technique. Five ramie fibers were mounted together parallel to each other onto the metal wire support 
to magnify mass change. Then the fibers were immersed into the distilled water by elevating the stage at a constant moving speed of $20 \mu \mathrm{m} / \mathrm{s}$. The exposure testing length in distilled water was $3 \mathrm{~mm}$ in order to gain rigidity. Each contact angle reported was an average of at least 3 measurements.

\subsection{XPS analysis}

The chemical composition of ramie fiber surfaces was analyzed using Thermo Scientific K-Alpha X-ray photoelectron spectrometer system (Thermo Scientific, USA) with an $\mathrm{Al} \mathrm{K} \alpha(1486.7 \mathrm{eV}) \mathrm{X}$-ray source. The pressure of the chamber was 3.2 $\times 10^{-7}$ mbar and the take-off angle was $45^{\circ}$. The deconvolution analysis of $\mathrm{C} 1 \mathrm{~s}$ spectra was carried out using XPSPEAK4.1 software.

\subsection{RGA analysis}

Molecular fragments genereated in plasma chamber were identified using a MKS instruments (Morgan Hill, CA) spectra products residual gas analysis (RGA) LM78/LM505 mass spectrometry system. The ratio $r$ of ion fragment abundance is defined as:

$r=\frac{A_{o}}{A_{f}}$

where $A_{\mathrm{o}}$ is the ion fragment abundance of outlet gas and $A_{f}$ is the ion fragment abundance of feeding gas.

\subsection{Microbond specimen preparation and test}

Microbond pullout tests were carried out to determine IFSS of the ramie/PP interface. Single PP fibers were tied onto the ramie fibers and then the specimens were heated at $180{ }^{\circ} \mathrm{C}$ for $30 \mathrm{~s}$, nearly uniform micro beads were formed. The 
embedded length, the fiber diameter and the bead width (see Fig. 2) were measured with a polarized light microscope (Olympus $\left.\mathrm{BH}_{2}\right)$.

The microbond test was conducted on a custom-made single fiber tensile testing system equipped with a microvise. The upper clamp displacement rate was 20 $\mathrm{mm} / \mathrm{min}$ and the load cell had a capacity of $1000 \mathrm{cN}$.

The interfacial shear strength (IFSS), $\tau_{i}$ was calculated using the following equation derived from the shear-lag model [18]:

$\tau_{\mathrm{i}}=\frac{n P_{\max } \operatorname{coth}(n L / r)}{2 A}$

Where $P_{\max }$ is the peak load, $L$ the embedded length, $r$ the radius of the fiber, $A$ the cross-sectional area of the fiber and $n$ is defined as:

$n=\left[\frac{E_{\mathrm{m}}}{E_{\mathrm{f}}\left(1+v_{\mathrm{m}}\right) \ln (R / r)}\right]^{1 / 2}$

Where $E_{\mathrm{m}}$ is the Young's modulus of the matrix $(1.75 \mathrm{GPa}), v_{\mathrm{m}}$ the Poisson's ratio of the matrix $(0.35), E_{\mathrm{f}}$ the tensile modulus of the fiber $(25 \mathrm{GPa})$ and $R$ is the radius of PP bead.

\section{Result and discussion}

\subsection{Surface morphology}

The SEM micrographs of the ramie fibers from the control, the DBD treated only group and the plasma-treated groups are exhibited in Fig. 3. It can be found that the surface of untreated ramie fiber was relatively smooth (Fig. 3a). For DBD treated only group, a rougher surface (Fig. 3b) was generated with some defects like spots and 
corrugations due to the energetic species such as electrons, ions and radicals in plasma collided with the fiber surface. For DBD plus ethanol treated group, no significant fiber surface defects caused by plasma over-etching were observed (Fig. 3c), because the ethanol molecules in continuous ethanol flow could react with active particles in plasma and then reduce the etching effect. Besides, there was no observed difference among all DBD plus ethanol treated groups, so only one SEM micrograph is presented for brevity.

\subsection{Dynamic water contact angle}

The dynamic water contact angle values of the DBD plus ethanol treated groups are presented in Fig.4. The dynamic contact angle of control group was $45.2^{\circ}$. For DBD treated only group, the contact angle decreased to $42.1^{\circ}$, which was mainly attributed to the increase in fiber surface roughness. For DBD plus ethanol treated group, it can be observed that the combined treatments effectively reduced the surface wettability of the ramie fibers, suggesting a layer of hydrophobic groups was successfully grafted onto ramie fiber surface with the introduction of continous flow of ethanol vapor. Besides, it is noteworthy that under certain optimal experimental conditions like 10 $\mathrm{mA}$ treatment current, $8 \mathrm{sccm}$ ethanol flow rate and 5 min treatment time (group9), highest dynamic contact angle of $82.7^{\circ}$ was obtained.

The three-dimensional response surfaces of dynamic contact angle generated as a result of the joint influence of plasma parameters are presented in Fig. 5a-5c. The diagrams indicate that the ethanol flow rate had significant influence on the increase of dynamic water contact angle of ramie fiber. Meanwhile, it can be noted that there 
were interaction effects between all variables (treatment current, treatment time and ethanol flow rate), suggesting that it was the simultaneous interaction of optimal experimental parameters, rather than the involvement of high parameters beneficial to an efficient plasma modification process.

\subsection{Interfacial shear strength}

The IFSS value was 16.7 MPa and 17.1 MPa for the untreated group and DBD treated only group, respectively. It was found all DBD plus ethanol treated groups had significant improvement in IFSS value (Fig. 6) compared with that of control group. In this experiment, the IFSS increased up to $50.3 \%$ for group 9 under treatment condition of $10 \mathrm{~mA}$ current, $8 \mathrm{sccm}$ flow rate and 5 min duration, which could be attributed to better chemical compatibility in the ramie/PP interface due to a grafted layer of hydrophobic groups on ramie fiber surface and better physical compatibility due to more mechanical interlocking caused by plasma etching.

The three-dimensional response surfaces for IFSS value generated as a result of the simultaneous influence of plasma parameters are presented in Fig. 7a-7c. It can be seen that flow rate was the most influential parameter in the process while the time and current were less effective, which is in agreement with DCAA test. It can be suggested that the hydrophobicity of ramie fiber surface played the most important role in improving the IFSS values while plasma surface etching was less effective in our experiment, perphaps because that the continous ethanol flow partially blocked the etching effect. Meanwhile, the result implies that there were interaction effects between current and flow rate as well as time and flow rate, further confirming that 
the plasma modification effect on ramie fiber surface was not solely based on one processing parameter.

\subsection{XPS analysis}

Table 2 shows the element composition and the atmic ratios of $\mathrm{O} / \mathrm{C}$ of the ramie fiber surfaces derived from the XPS spectra. The control group had relatively high ratio of oxygen to carbon about 0.48 . For DBD treated only group, this ratio increased slightly to 0.53 , due to the oxidation process during plasma treatment. For DBD plus ethanol treated group, this ratio remarkably decreased to minimum value of 0.20 , which is mainly attributed to the chemical reaction between the ethanol molecules to cellulose in plasma environment of continuous ethanol flow, forming a grafted layer of ethyl groups on the ramie fiber surfaces.

The deconvolution analusis of $\mathrm{C} 1 \mathrm{~s}$ peaks was carried out using Gaussian-Lorentzian fit in order to obtain further insight into the chemical bonds present on the ramie fiber surfaces. The $\mathrm{C} 1 \mathrm{~s}$ peaks were fitted into four peaks corresponding to C-C (285 eV), C-O (286.5 eV), C=O (288.1 eV), O=C-O $(289.4 \mathrm{eV})$ as presented in Fig. 8 and the results are shown in Table 2. For DBD plus ethanol treated group, an incease of $\mathrm{C}-\mathrm{C}$ bond and a decrease of oxygen-containing bonds were observed. The C-C bond had an increase up to $81 \%$ after combined treatments, mainly due to the grafted layer of ethyl groups as mentioned before. The results showed that the introduction of ethanol vapor channel into plasma chamber was beneficial to decreasing the polar groups like hydroxyl groups on cellulose even with very low amount of ethanol, which was a high-efficient and low-cost surface 
modification method for cellolusic fibers.

\subsection{RGA analysis}

The residual gas analysis (RGA) indicates that the main molecular ion fragments of ethanol were: $\mathrm{CH}_{3} \mathrm{CH}_{2}-(\mathrm{m} / \mathrm{z}=29), \mathrm{CH}_{3} \mathrm{CH}_{2} \mathrm{O}-(\mathrm{m} / \mathrm{z}=45)$ and $\mathrm{CH}_{3} \mathrm{CH}_{2} \mathrm{OH}$ $(\mathrm{m} / \mathrm{z}=46)$. The contour diagram for the response surface of ratio $r$ for $\mathrm{CH}_{3} \mathrm{CH}_{2}-$ groups versus treatment current and flow rate is presented in Fig.9.

. From Table 3, it was found that $r$ values for $\mathrm{CH}_{3} \mathrm{CH}_{2} \mathrm{O}-(\mathrm{m} / \mathrm{z}=45)$ and $\mathrm{CH}_{3} \mathrm{CH}_{2} \mathrm{OH}(\mathrm{m} / \mathrm{z}=46)$ were less than 1 , suggesting consumption of these two types of groups during plasma treatment. Meanwhile, $r$ value for $\mathrm{CH}_{3} \mathrm{CH}_{2}-(\mathrm{m} / \mathrm{z}=29)$ was higher than 1, indicating the creation of $\mathrm{CH}_{3} \mathrm{CH}_{2}-$ groups during plasma treatment by ethanol fragmentation. The result implies that the $\mathrm{CH}_{3} \mathrm{CH}_{2} \mathrm{OH}$ was partially converted into $\mathrm{CH}_{3} \mathrm{CH}_{2}-$ groups during plasma modification process. Besides, it is noted that maximum abundance of $\mathrm{CH}_{3} \mathrm{CH}_{2}-$ groups was achieved when current was higher than $8 \mathrm{~mA}$ and ethanol flow rate was higher than $3.5 \mathrm{sccm}$, which could be explained by that with the increase of treatment current and flow rate, more active plasma species with sufficiently high energy could fragment the molecular bonds to form $\mathrm{CH}_{3} \mathrm{CH}_{2}-$ groups and to deposit a hydrophobic layer on fiber surface. Furthermore, the results of dynamic contact angle and IFSS correlate well with RGA analysis, indicating that there was strong relationship between the abundance of $\mathrm{CH}_{3} \mathrm{CH}_{2}-$ groups and plasma modification effects. 


\section{Conclusion}

A statistical central composite design of experiments of plasma modification on ramie fibers for better interfacial adhesion between fibers and PP matrices was conducted. The results showed that our continuous ethanol flow technique can successfully modify ramie fiber surface: The IFSS value of the treated group significantly increased up to $50 \%$ compared with the control group, which was obtained under treatment condition of $10 \mathrm{~mA}$ current, $8 \mathrm{sccm}$ ethanol flow rate and 5 min duration. The improvement in interfacial adhesion can be attributed to a combination of improved surface hydrophobicity of ramie fiber due to the creation of ethyl groups and more mechanical interlocking due to etching effect during plasma treatment. Meanwhile, it also can be noted the ethanol flow rate played the most influential role in this process and all processing parameters have interaction effects on ramie fiber modification effect.

\section{Acknowledgements}

This work was supported by the Chinese Scholarship Council and S-1054 Hatch Federal funding. The authors acknowledge use of instrumentation supported by the University of Wisconsin, College of Engineering and the following NSF CENTERS material research and Engineering Center (NSF-DMR-1121288) Nanoscale Science and Engineering Center (NSF-DMR-0832760). 


\section{Figure Captions}

Fig. 1. Exploded view of DBD sealed reactor.

Fig. 2. Polarized light microscope photograph of a micro bead for the microbond pullout test.

Fig. 3. SEM micrographs of ramie fibers: (a) control group, (b) DBD treated only group, (c) DBD plus ethanol treated group.

Fig. 4. The dynamic water contact angle values of DBD plus ethanol treated groups.

Fig. 5. The The three-dimensional response surfaces of dynamic contact angle versus (a) current and flow rate; (b) current and time; (c) time and flow rate.

Fig. 6. The IFSS values of DBD plus ethanol treated groups.

Fig. 7. The three-dimensional response surfaces of IFSS values versus (a) current and flow rate; (b) current and time; (c) time and flow rate.

Fig. 8. Deconvoluted XPS C1s spectra for: (a) control group, (b) DBD treated only group, (c) DBD plus ethanol treated group.

Fig. 9. The contour diagram for the response surface of ratio $r$ for $\mathrm{CH}_{3} \mathrm{CH}_{2}-$ groups versus treatment current and flow rate.

\section{References}

[1] L.J. Liu, C.Y. Lao, N. Zhang, H.Q. Chen, G. Deng, C. Zhu, D.X. Peng, The effect of new continuous harvest technology of ramie (Boehmeria nivea L. Gaud.) on fiber yield and quality, Ind. Crops Prod. 44 (2013) 677-683.

[2] Y. Du, N. Yan, M.T. Kortschot, The use of ramie fibers as reinforcements in 
composites, in: O. Faruk, M. Sain (Eds.), Biofiber Reinforcements in Composite Materials, Woodhead Publishing, Cambrige, 2015, pp. 104-137.

[3] A.K. Bledzki, S. Reihmane, J. Gassan, Properties and modification methods for vegetable fibers for natural fiber composites, J. Appl. Polym. Sci. 59 (1996) $1329-1336$.

[4] C.A.S. Hill, H.P.S.A. Khalil, M.D. Hale, A study of the potential of acetylation to improve the properties of plant fibres, Ind. Crops Prod. 8 (1998) 53-63.

[5] G. Kalaprasad, B. Francis, S. Thomas, C.R. Kumar, C. Pavithran, G. Groeninckx, S. Thomas, Effect of fibre length and chemical modifications on the tensile properties of intimately mixed short sisal/glass hybrid fibre reinforced low density polyethylene composites, Polym. Int. 53 (2004) 1624-1638.

[6] N.L. Moigne, M. Longerey, J.M. Taulemesse, J.C. Bénézet, A. Bergeret, Study of the interface in natural fibres reinforced poly(lactic acid) biocomposites modified by optimized organosilane treatments, Ind. Crops Prod. 52 (2014) 481-494.

[7] X. Li, L.G. Tabil, S. Panigrahi, Chemical treatments of natural fiber for use in natural fiber-reinforced composites: A review, J. Polym. Environ. 15 (2007) 25-33.

[8] D. Ray, B.K. Sarkar, A.K. Rana, N.R. Bose, Effect of alkali treated jute fibres on composite properties, B. Mater. Sci. 24 (2001) 129-135.

[9] Y. Seki, Innovative multifunctional siloxane treatment of jute fiber surface and its effect on the mechanical properties of jute/thermoset composites, Mater. Sci. Engi. A. 508 (2009) 247-252.

[10] K. Sever, M. Sarikanat, Y. Seki, G. Erkan, Ü.H. Erdoğan, The mechanical 
properties of $\gamma$-methacryloxypropyltrimethoxy silane-treated jute/polyester composites, J. Compos. Mater. 44 (2010) 1913-1924.

[11] R. Morent, N.D. Geyter, J.Verschuren, K.D. Clerck, P. Kiekens, C. Leys, Non-thermal plasma treatment of textiles, Surf. Coat. Tech. 202 (2008) 3427-3449.

[12] S. Adeel, M. Usman, W. Haider, M. Saeed, M. Muneer, M. Ali, Dyeing of gamma irradiated cotton using Direct Yellow 12 and Direct Yellow 27: Improvement in colour strength and fastness properties, Cellulose. 22 (2015) 2095-2105.

[13] T. Gulzar, S. Adeel, I. Hanif, F. Rehman, R. Hanif, M, Zuber, N. Akhtar, Eco-friendly dyeing of gamma ray induced cotton using natural Quercetin extracted from acacia bark (A. nilotica). J. Natural Fibers. 12 (2015) 494-504.

[14] M. Saeed, S. Adeel, M.A. Shahzad, A.U. Haq, M. Muneer, M. Younas, $\mathrm{Pt} / \mathrm{Al}_{2} \mathrm{O}_{3}$ catalyzed decolorization of rhodamine B Dye in aqueous medium, Chaing Mai J. Sciecne. 42 (2015) 730-744.

[15] M. Muneer, S. Adeel, I.A. Bhatti, M.A. Jamal, F.U. Rehman, Removal of reactive orange P3r dye by oxidative pathway, Oxid. Commun. 38 (2015) 808-817.

[16] S. Adeel, M. Usman, W. Haider, A. Ghaffar, F. Rehman, M. Ali, Dyeing of biotreated and gamma irradiated cotton fabric using Direct Yellow 12 and Direct 27, J. Natural Fibers. (2015) In press.

[17] M. Ajmal, S. Adeel, M. Azeem, M. Zuber, N. Akhtar, N. Iqbal, Modulation of pomegranate peel colourant characteristics for textile dyeing using energy radiations, Ind. Crops Prod. 58 (2014) 188-193.

[18] I.A. Bhatti, S. Adeel, H. Taj, Application of Vat Green 1 dye on gamma ray 
treated cellulosic fabric, Radiat. Phys. Chem. 102 (2014) 124-127.

[19] S. Adeel, F.U. Rehman, R. Hanif, M. Zuber, E.U. Haq, M. Munir, Ecofriendly dyeing of UV-irradiated cotton using extracts of acacia nilotica bark (kikar) as source of natural flavones dye (quercetin), Asian J. Chem. 26 (2014) 830-834.

[20] A.A. Khan, N. Iqbal, S. Adeel, M. Azeem, F. Batool, I.A. Bhatti, Extraction of natural dye from red calico leaves: gamma ray assisted improvements in colour strength and fastness, Dyes Pigments. 103 (2014) 50-54.

[21] I.A. Bhatti, S. Adeel, S. Siddique, M. Abbas, Effect of UV radiations on dyeing of cotton fabric with Reactive Blue 13, J. Saudi Chem. Soc. 18 (2014) 606-609.

[22] C.N. Flynn, C.P. Byrne, B.J. Meenan, Surface modification of cellulose via atmospheric pressure plasma processing in air and ammonia-nitrogen gas, Surf. Coat. Tech. 233 (2013) 108-118.

[23] Z. Gao, S. Peng, J. Sun, L. Yao, Y. Qiu, Influence of processing parameters on atmospheric pressure plasma etching of polyamide 6 films, Appl. Surf. Sci. 255 (2009) 7683-7688.

[24] E.M. Liston, L. Martinu, M.R. Wertheimer, Plasma surface modification of polymers for improved adhesion: a critical review, J. Adhes. Sci. Technol. 7 (1993) $1091-1127$

[25] Y. Ren, C. Wang, Y. Qiu, Aging of surface properties of ultra high modulus polyethylene fibers treated with $\mathrm{He} / \mathrm{O}_{2}$ atmospheric pressure plasma jet, Surf. Coat. Tech. 202 (2008) 2670-2676.

[26] Y. Li, S. Moyo, Z. Ding, Z. Shan, Y. Qiu, Helium plasma treatment of 
ethanol-pretreated ramie fabrics for improving the mechanical properties of ramie/polypropylene composites, Ind. Crops Prod. 51 (2013) 299-305.

[27] Y. Li, J. Zhang, P. Cheng, J. Shi, L. Yao, Y. Qiu, Helium plasma treatment voltage effect on adhesion of ramie fibers to polybutylene succinate, Ind. Crops Prod. 61 (2014) 16-22.

[28] C. Zhang, Y. Qiu, Modified shear lag model for fibers and fillers with irregular cross-sectional shapes, J. Adhes. Sci. Technol. 17 (2003) 397-408. 


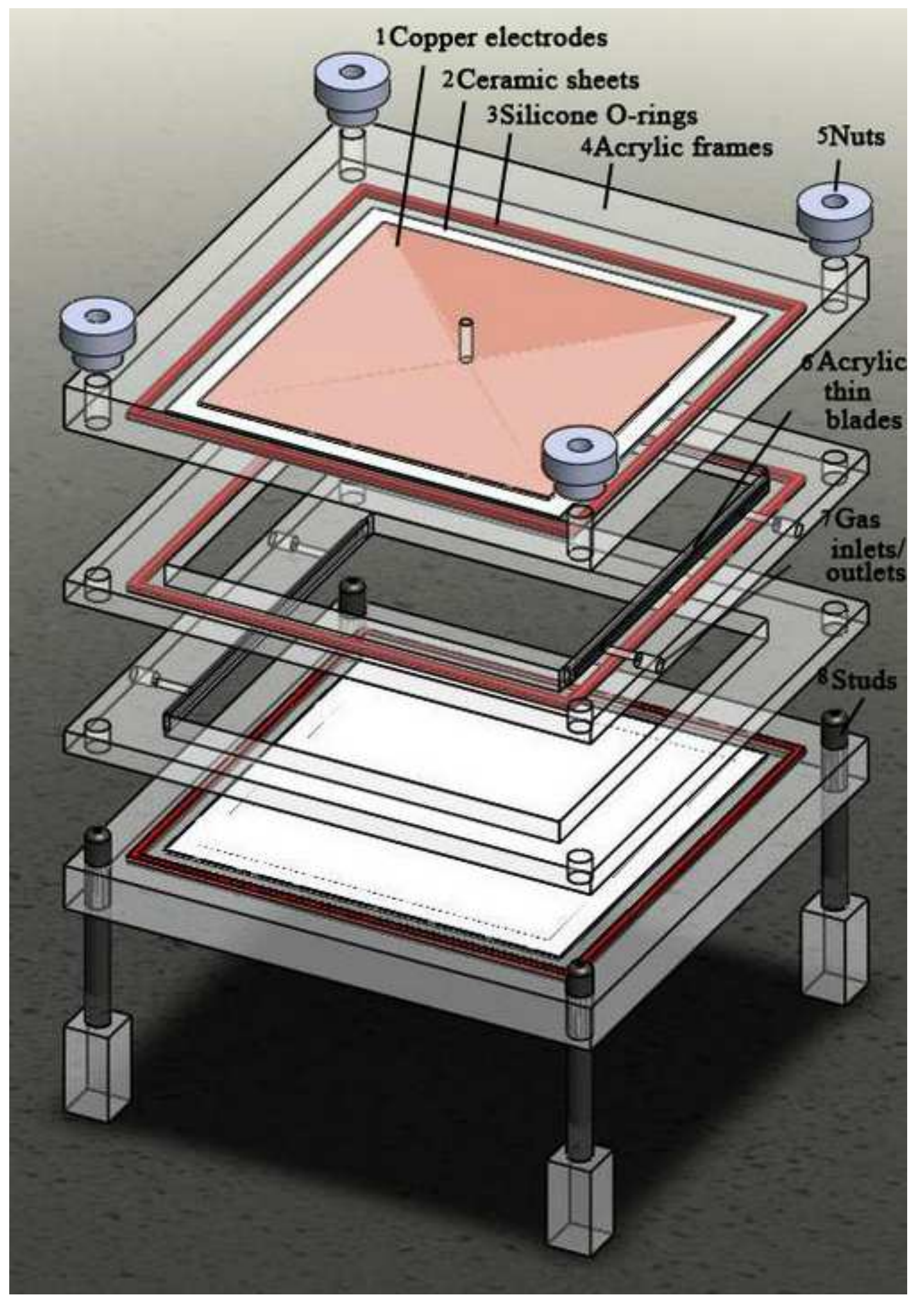


Fig.2

Fiber diameter Fiber width

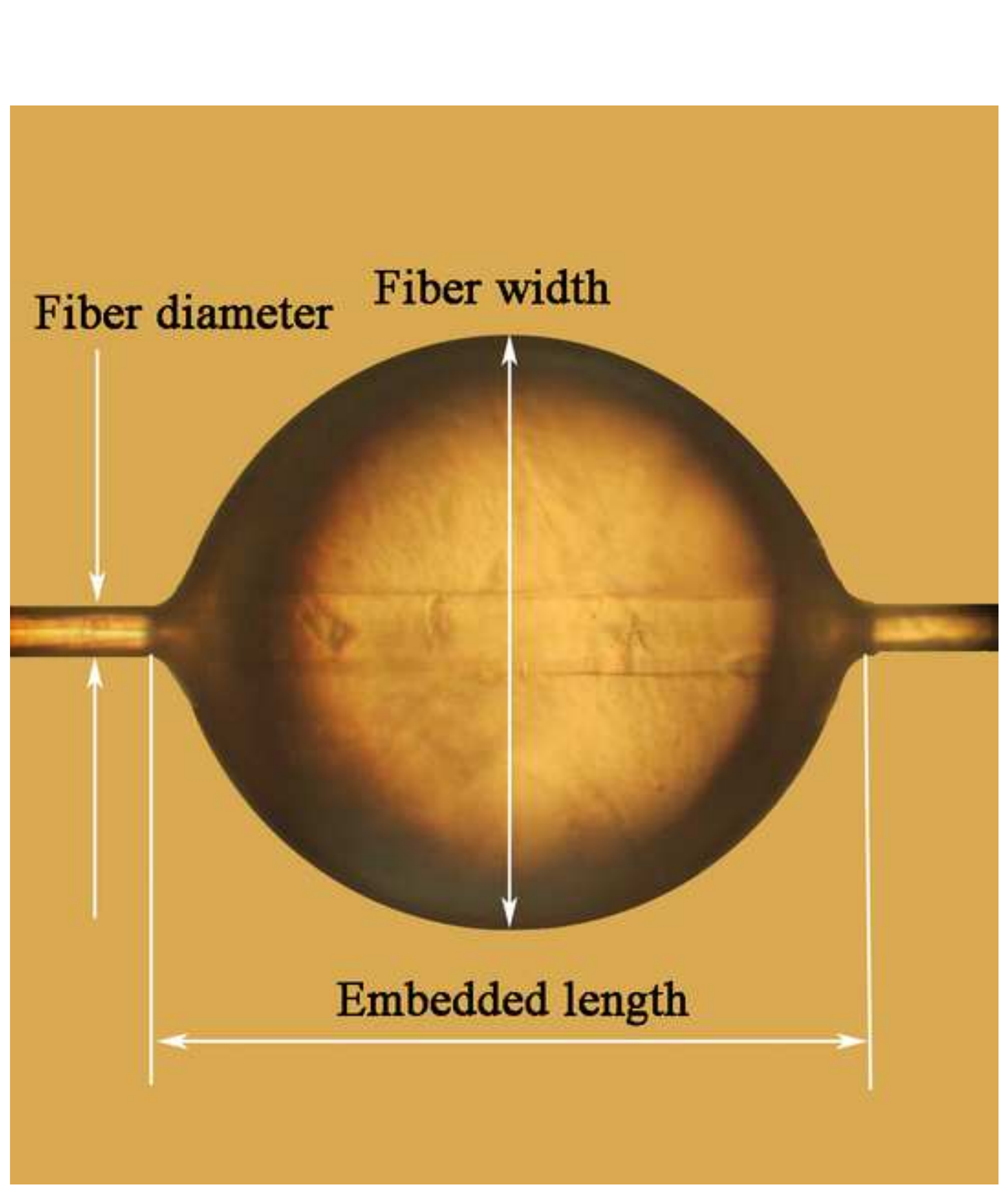

\section{Embedded length}




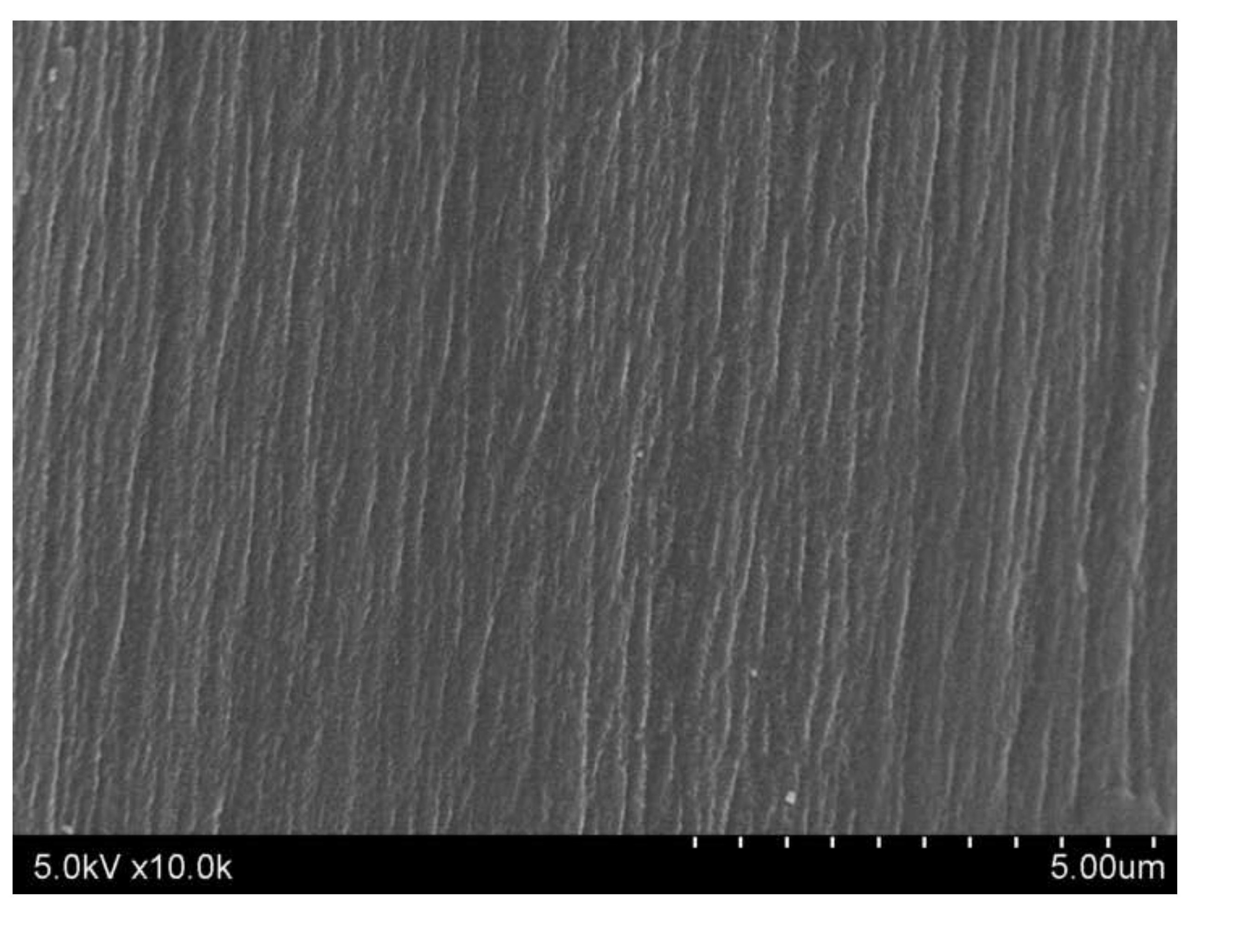



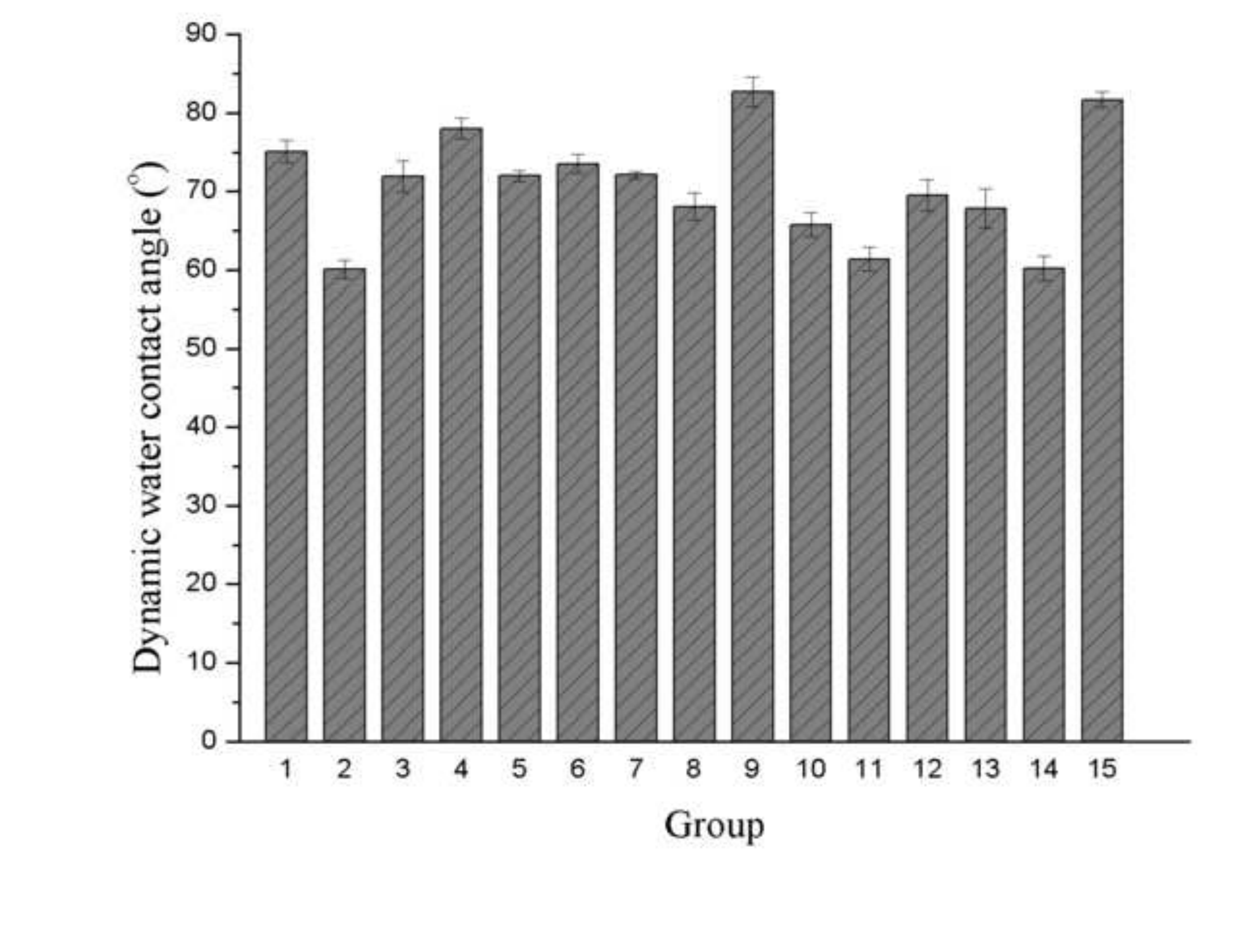
Group

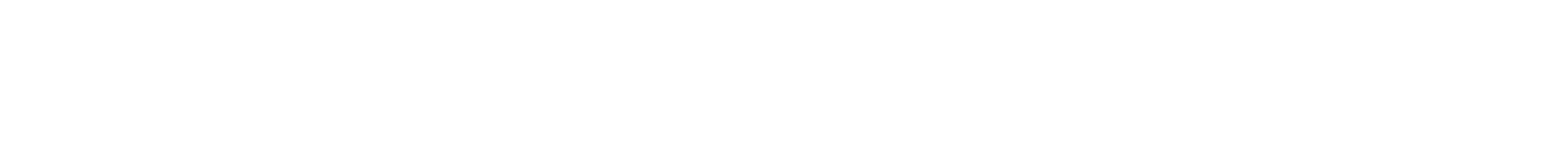

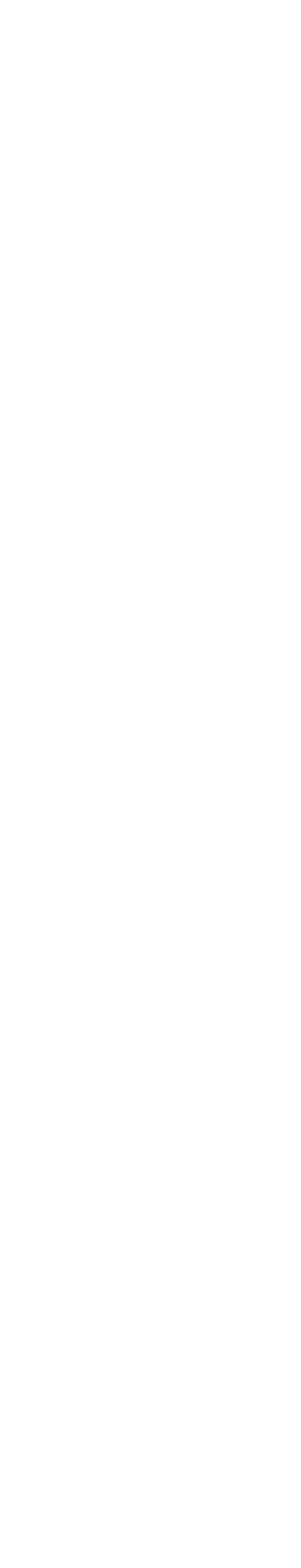

.

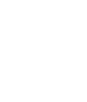
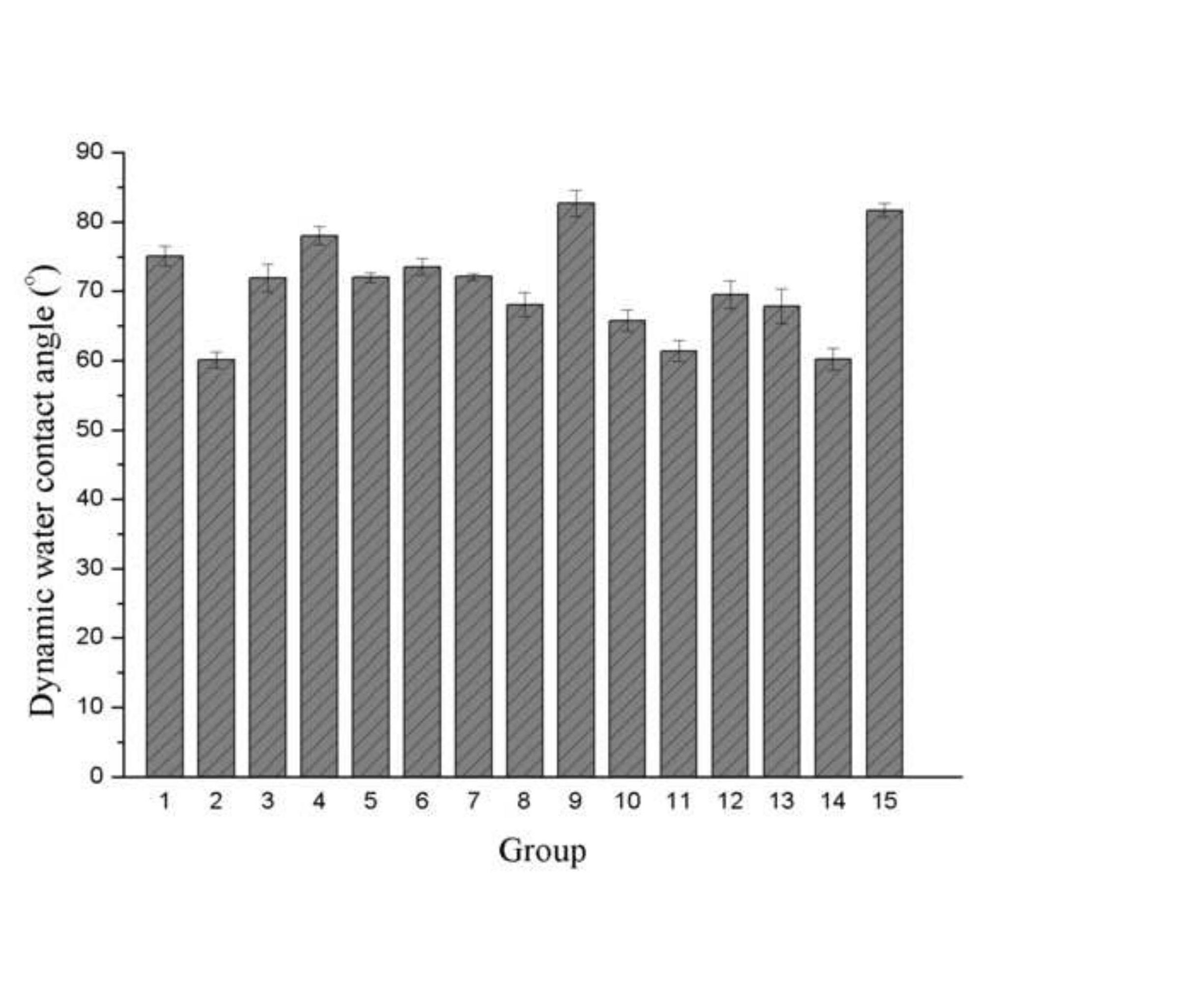


\section{Design Expert Software}

\section{Factor Coding: Actual}

R1

- Design points above predicted value

- Design points below predicted value

$\left[\begin{array}{l}82.7 \\ 60.1\end{array}\right.$

$\mathbf{X 1}=\mathbf{A}:$ Current

$\mathbf{X} 2=\mathbf{B}$ : Flow

Actual Factor

C: Time $=\mathbf{5 . 0 0}$

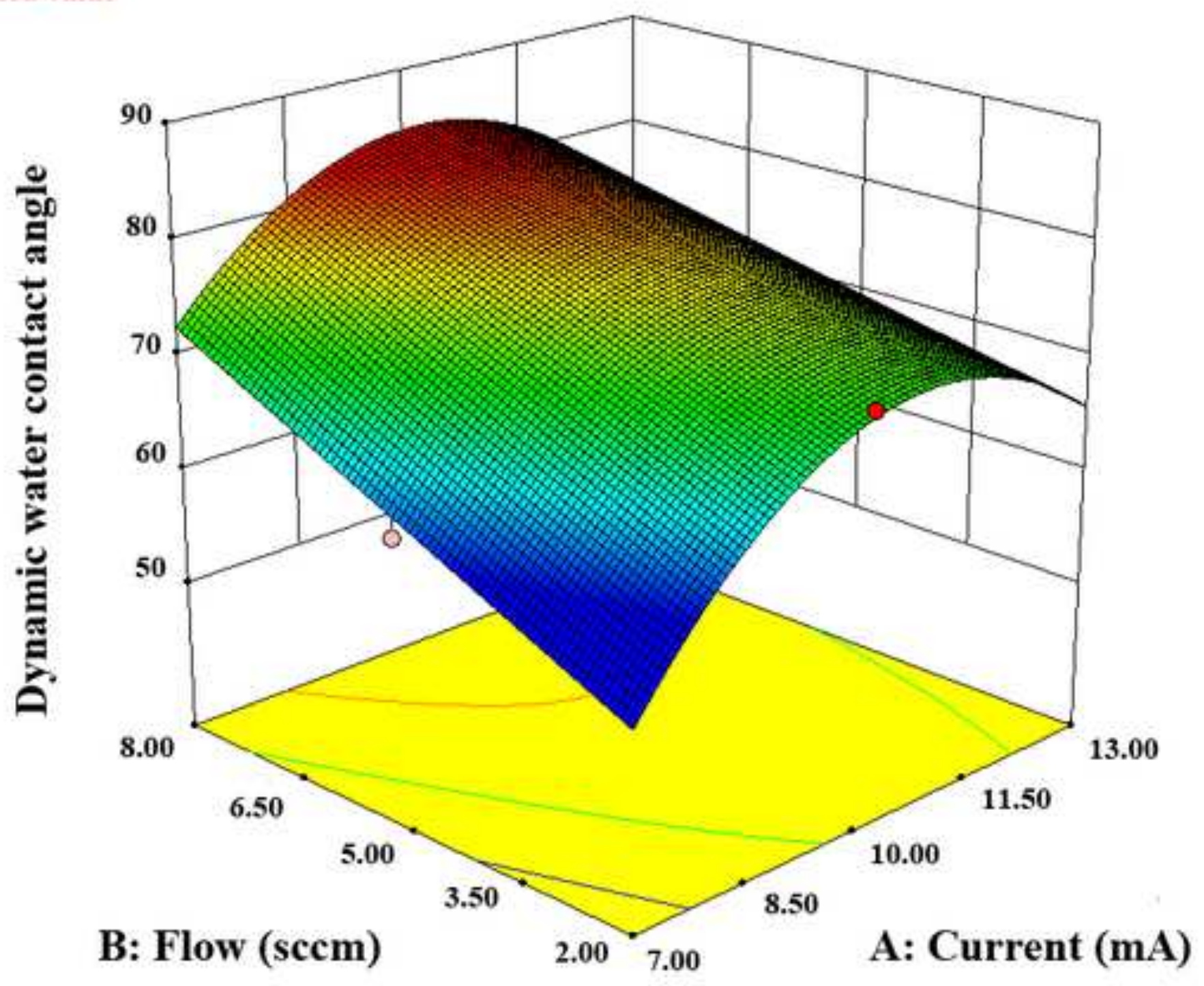




\section{Design Expert Software}

\section{Factor Coding: Actual}

R1

- Design points above predicted value

- Design points below predicted value

$\left[\begin{array}{l}82.7 \\ 60.1\end{array}\right.$

X1 - A:Current

X2 = C:Time

Actual Factor

B:Flow - $\mathbf{5 . 0 0}$

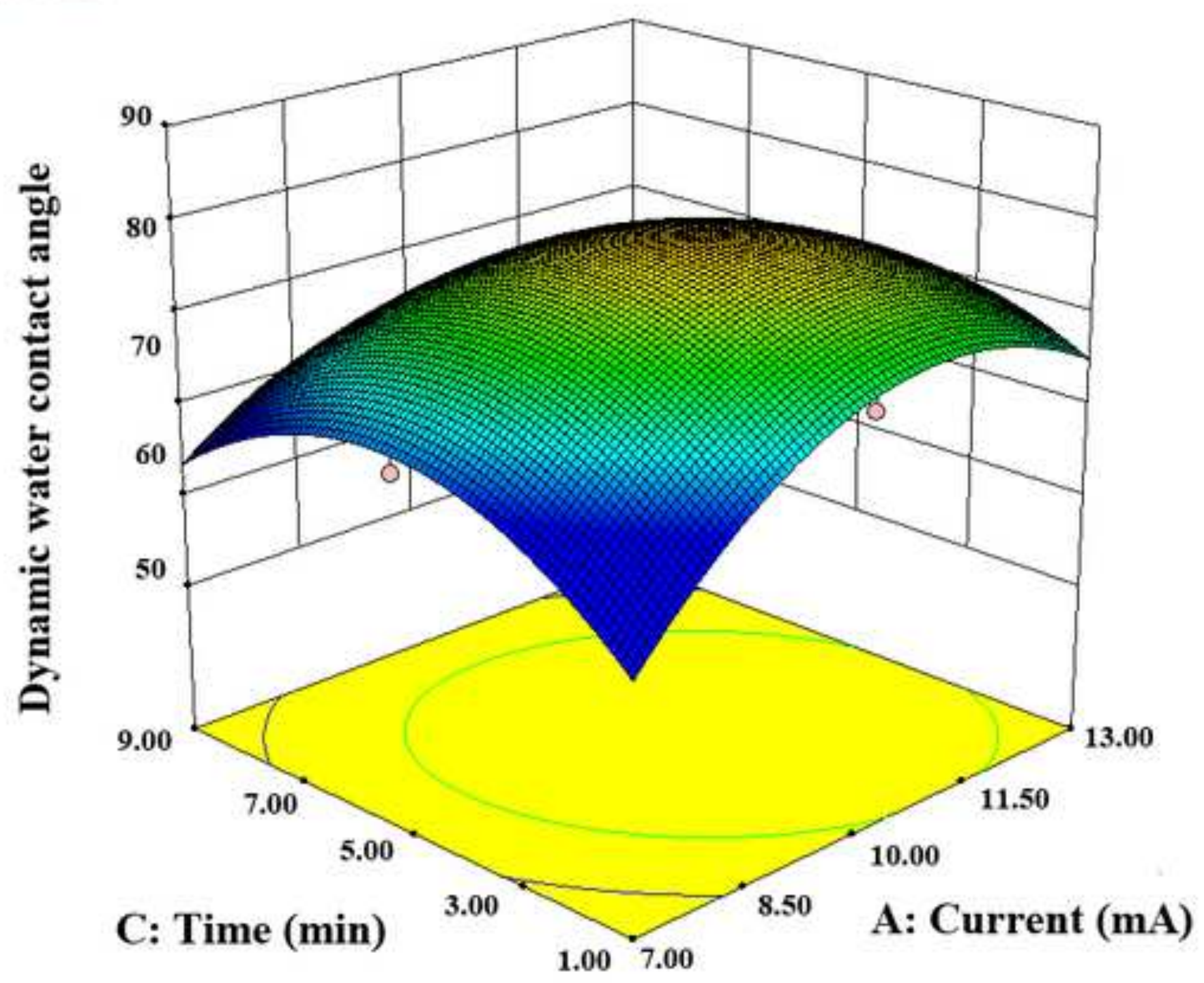




\section{Design Expert Software}

Factor Coding: Actual

R1

- Design points above predicted value

- Design joints below predicted value

60.1

$\mathbf{X} 1=\mathbf{B}:$ Flow

$\mathbf{X} 2$ = : Time

Actual Factor

A:Current - $\mathbf{1 0 . 0 0}$

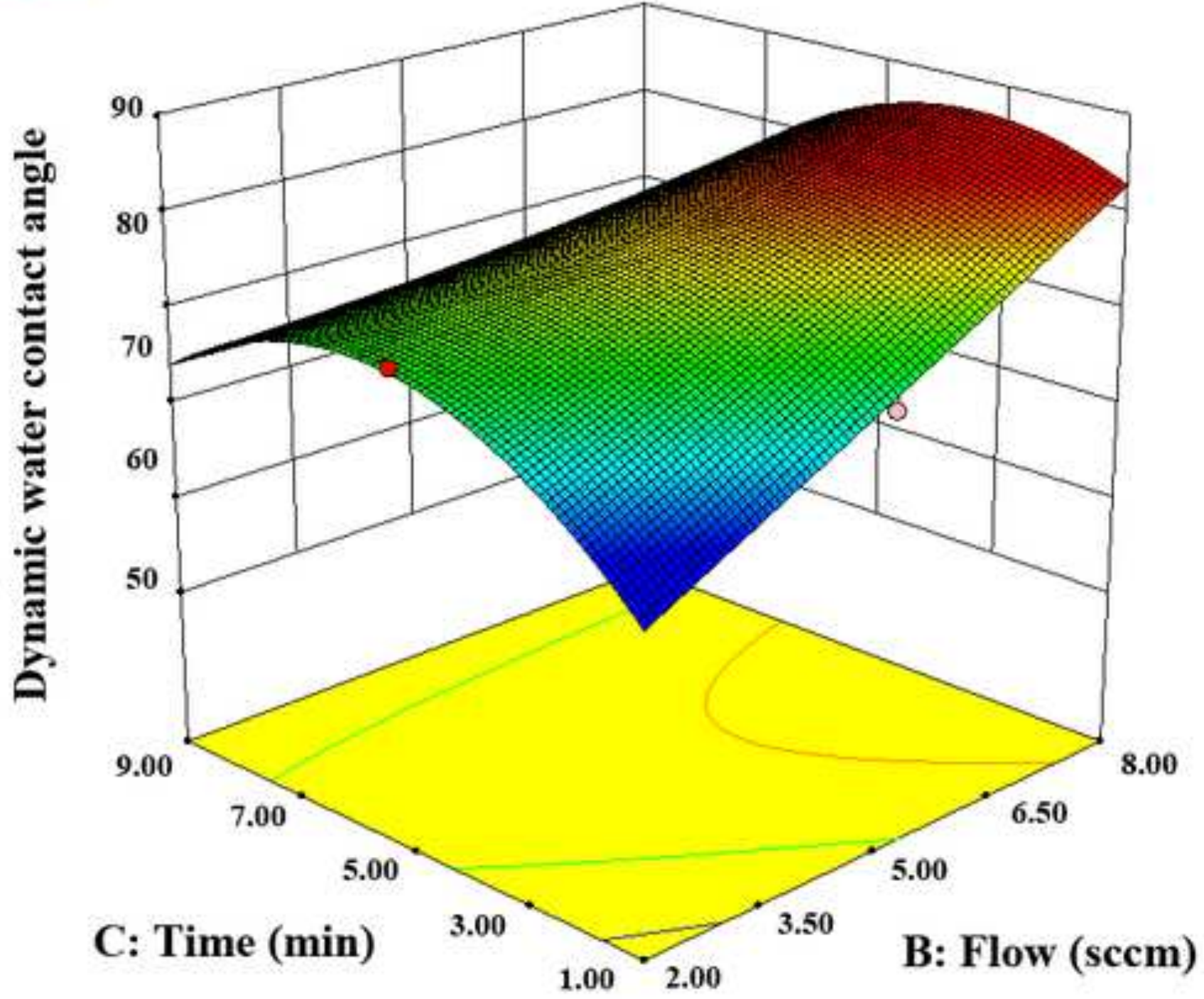




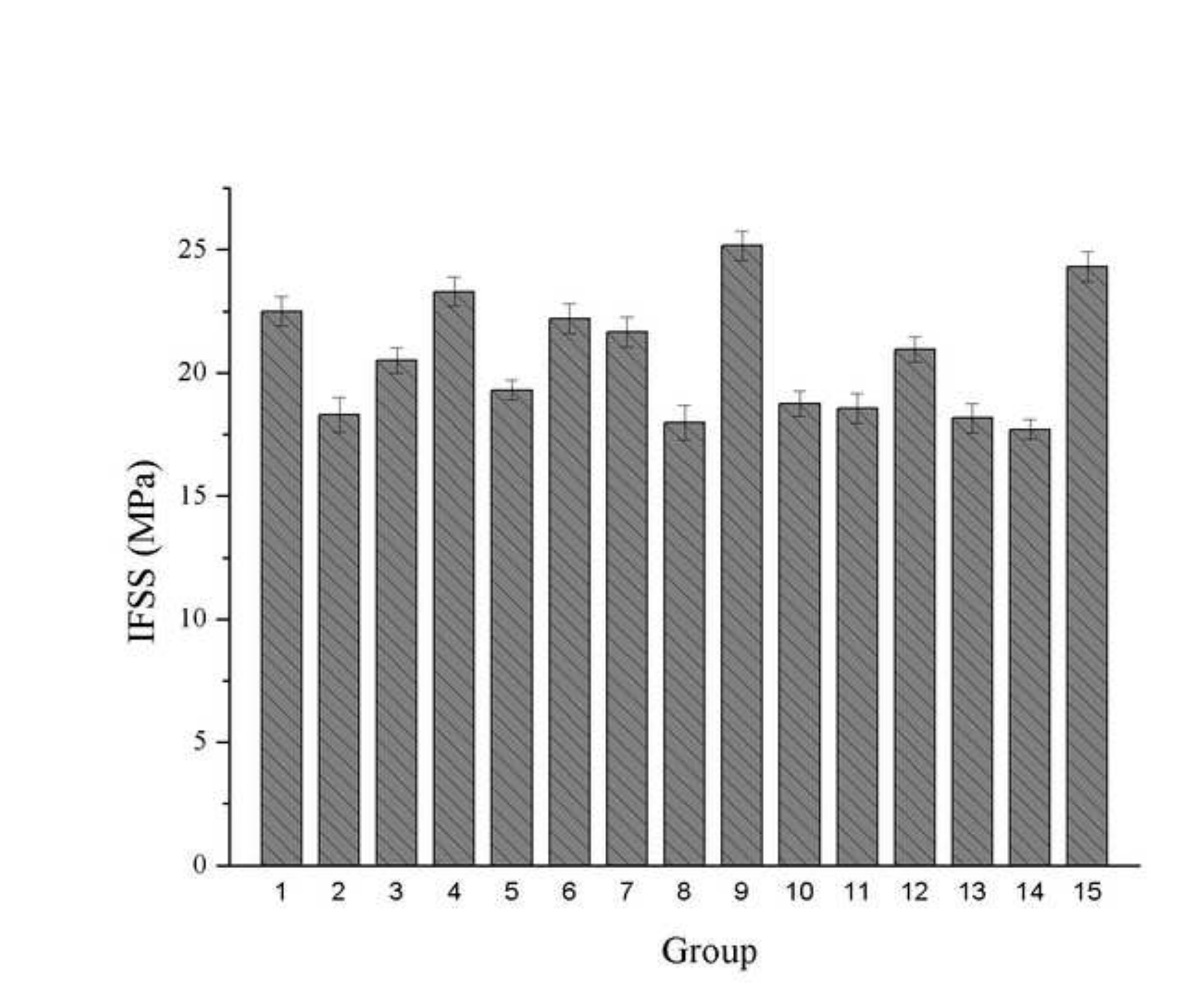

.

.




\section{Design Expert Software}

\section{Factor Coding: Actual}

R1

- Design points above predicted value

- Design points below predicted value

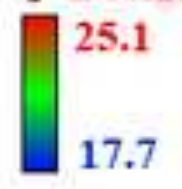

X1 = A:Current

$\mathrm{X} 2=\mathrm{B}:$ Flow

Actual Factor

C: Time $=\mathbf{5 . 0 0}$

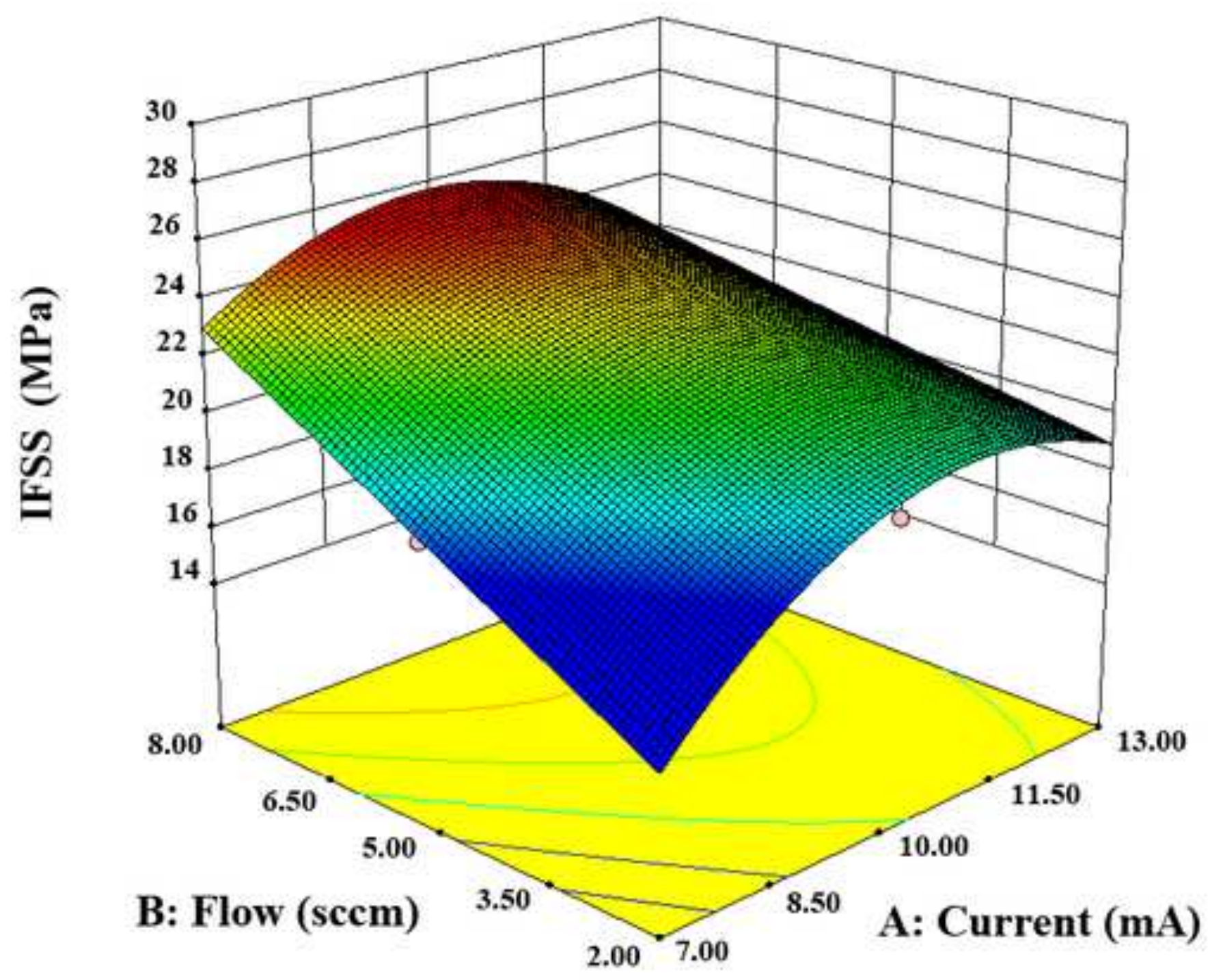




\section{Design Expert Software}

\section{Factor Coding: Actual}

R1

- Design points above predicted value

- Desigu points below predicted value

$\prod_{17.7}^{25.1}$
X1 - A:Current
X2 = C:Time

Actual Factor

B:Flow $-\mathbf{5 . 0 0}$

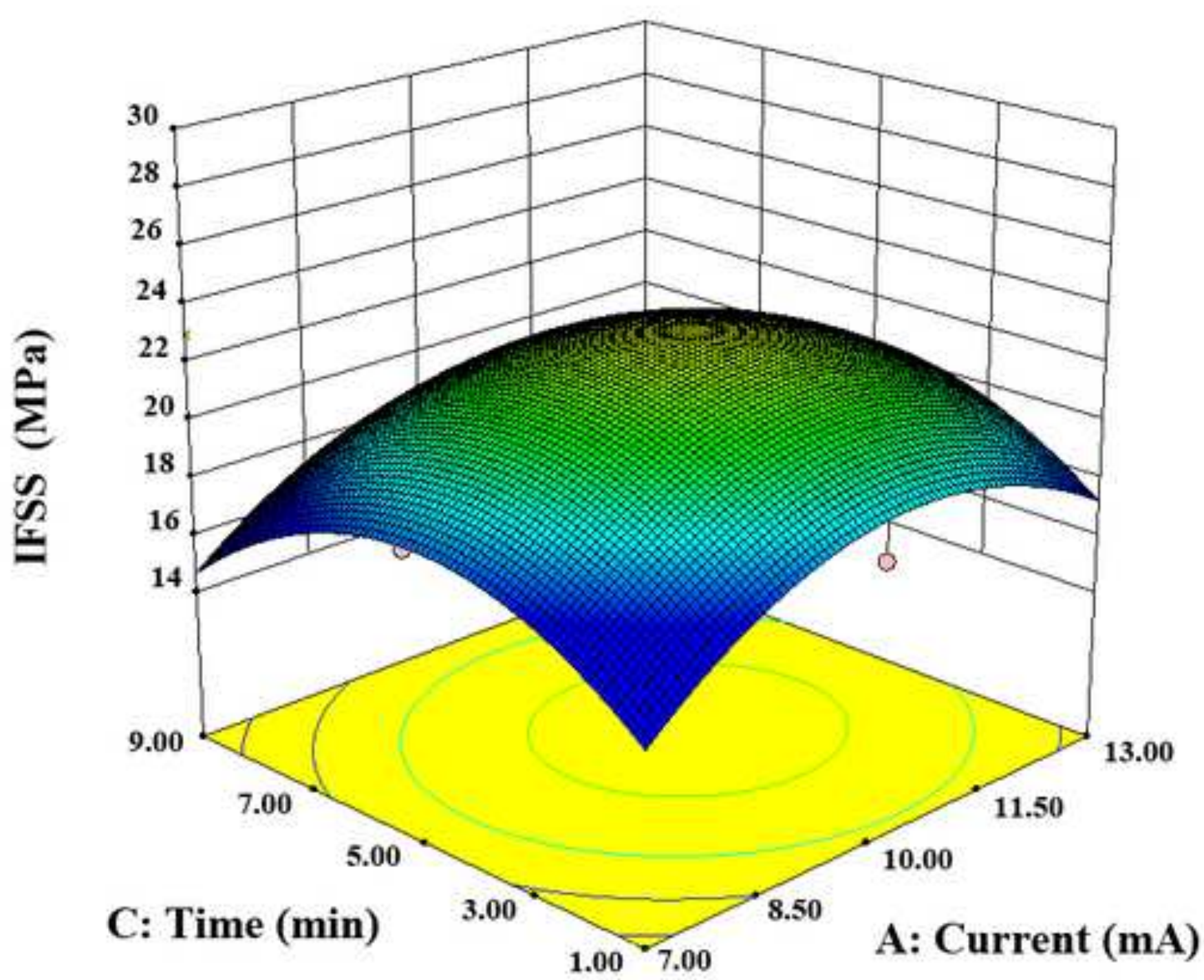




\section{Design Expert Software}

\section{Factor Coding: Actual}

R1

- Design points above predicted value

- Design points below predicted value

$$
\begin{aligned}
& \square^{25.1} \\
& \mathbf{X} .7 \\
& \mathbf{X}=\text { B:Flow } \\
& \mathrm{X} 2=\text { C:Time }
\end{aligned}
$$

Actual Factor

A:Current - 10.00

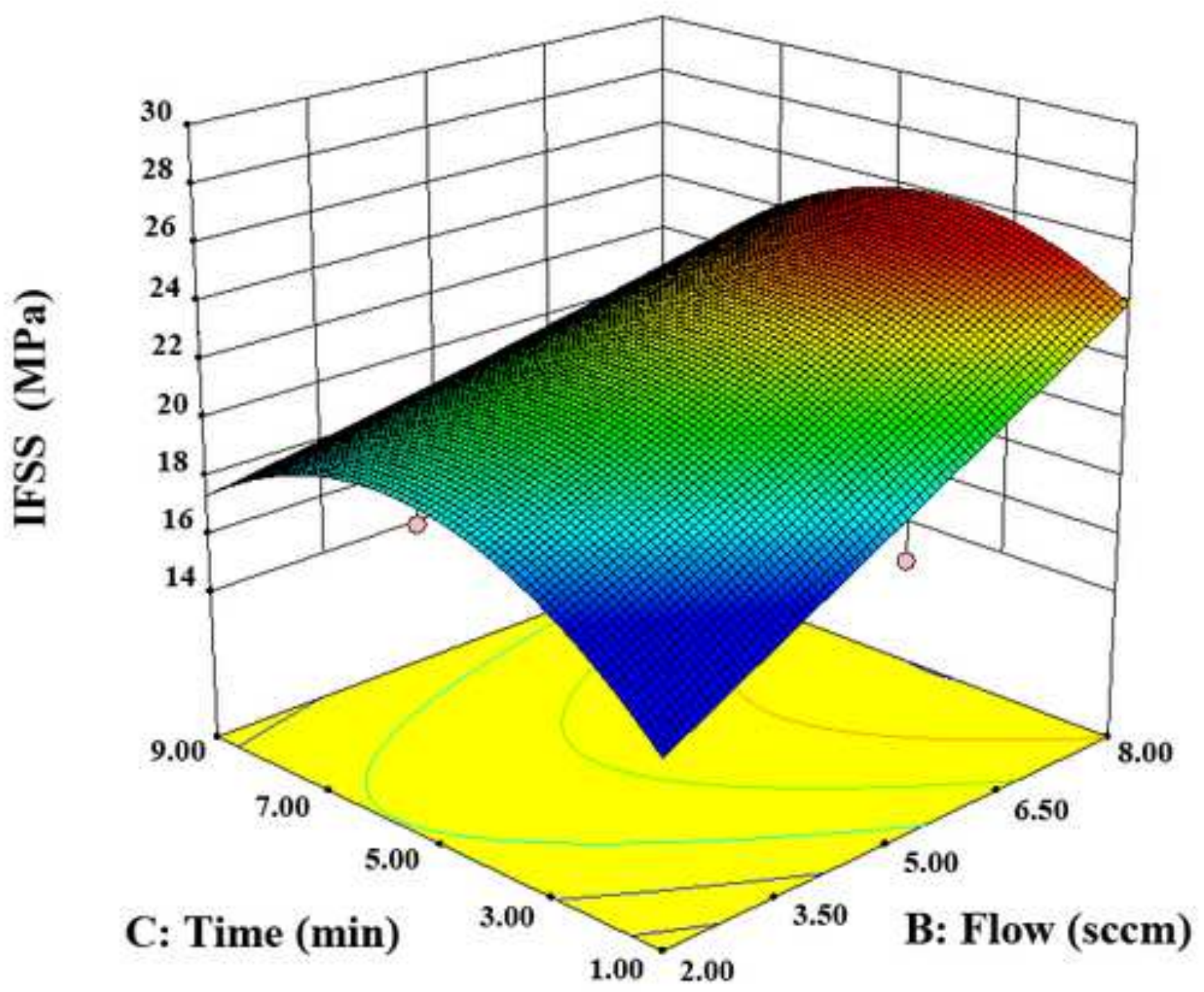


Fig.8a
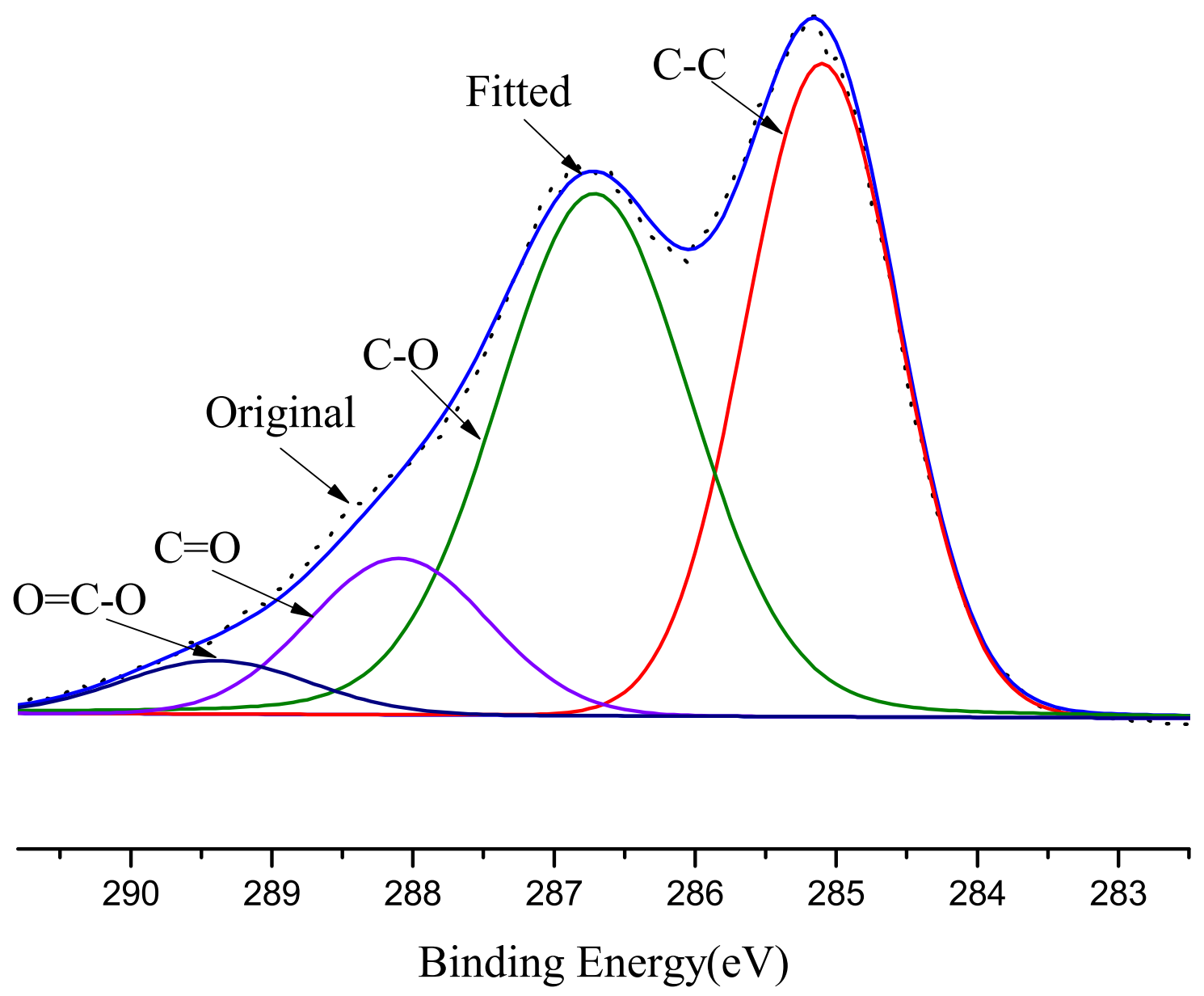
Fig.8b

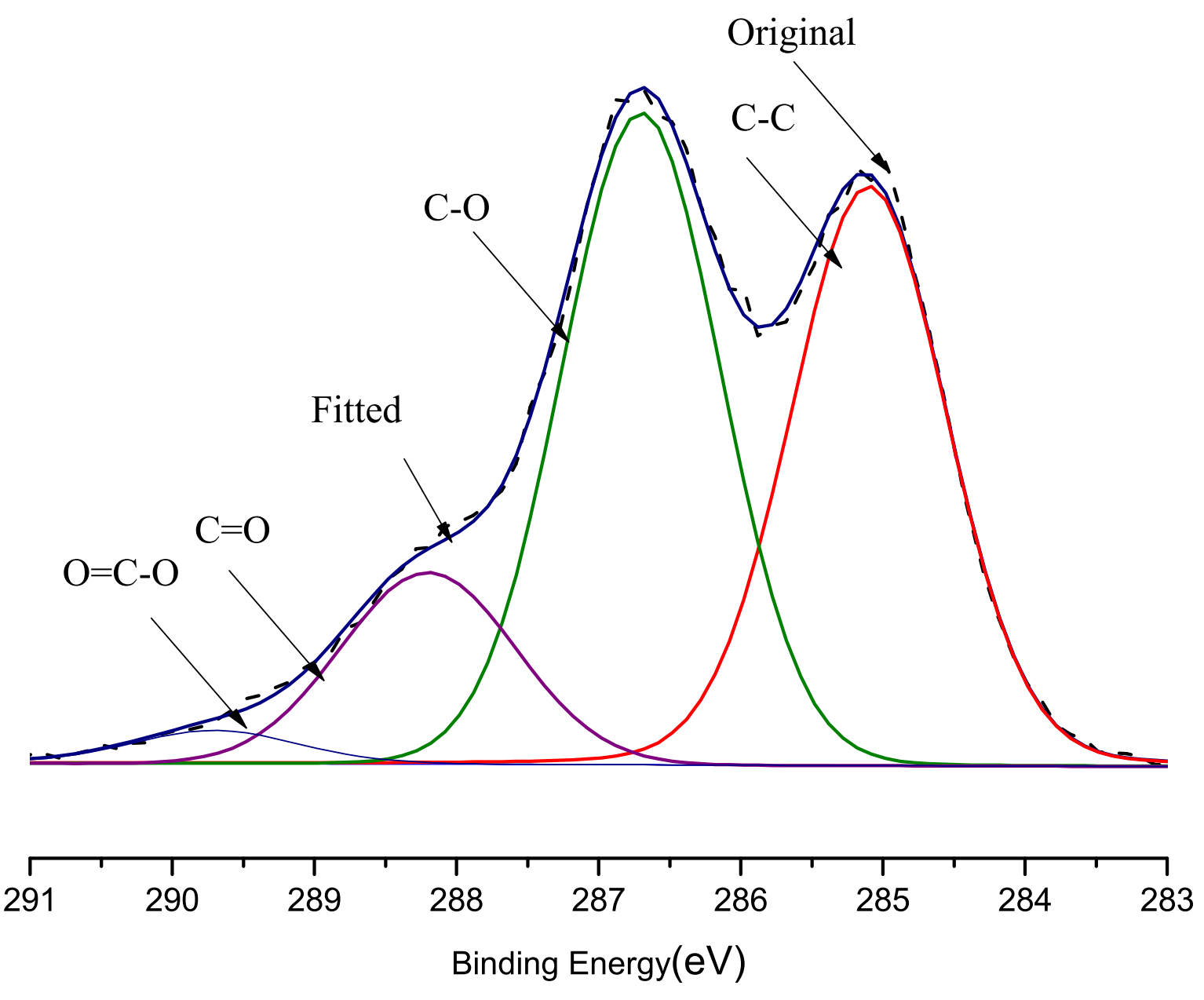


Fig.8c

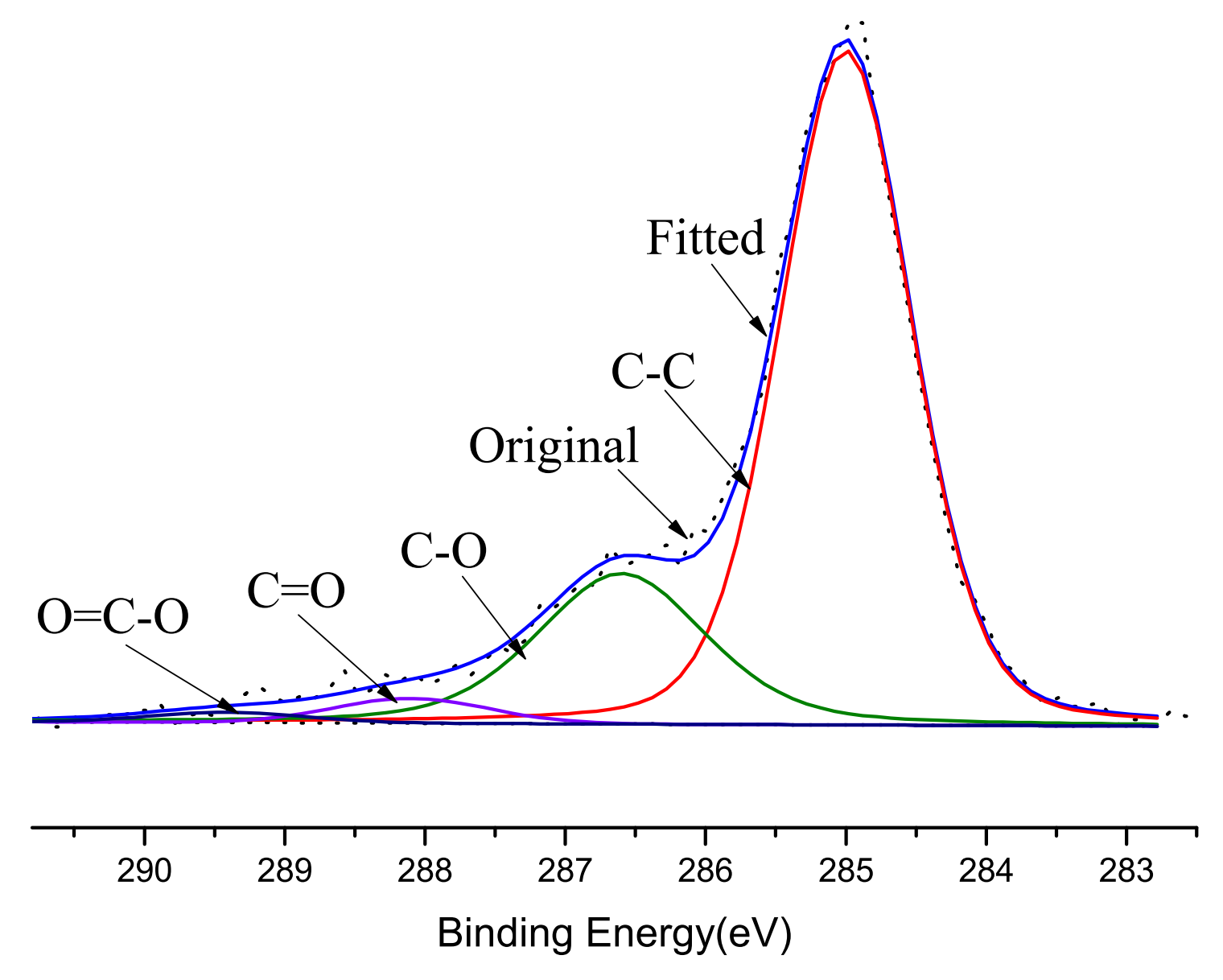




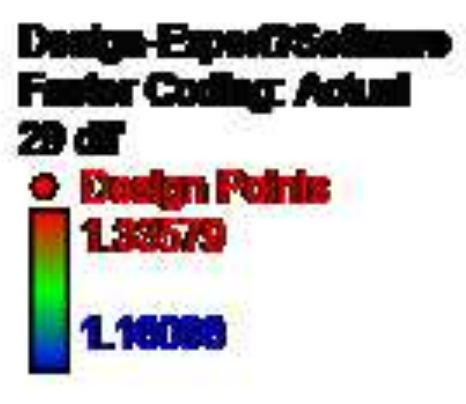

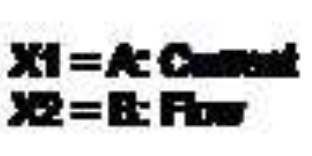 \\ $\mathrm{X}_{1}=\mathrm{AC}$
$\mathrm{z}=\mathrm{E} \mathrm{F}$ \\ Fatrain \\ 20.

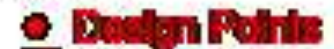 \\ 24.1.}

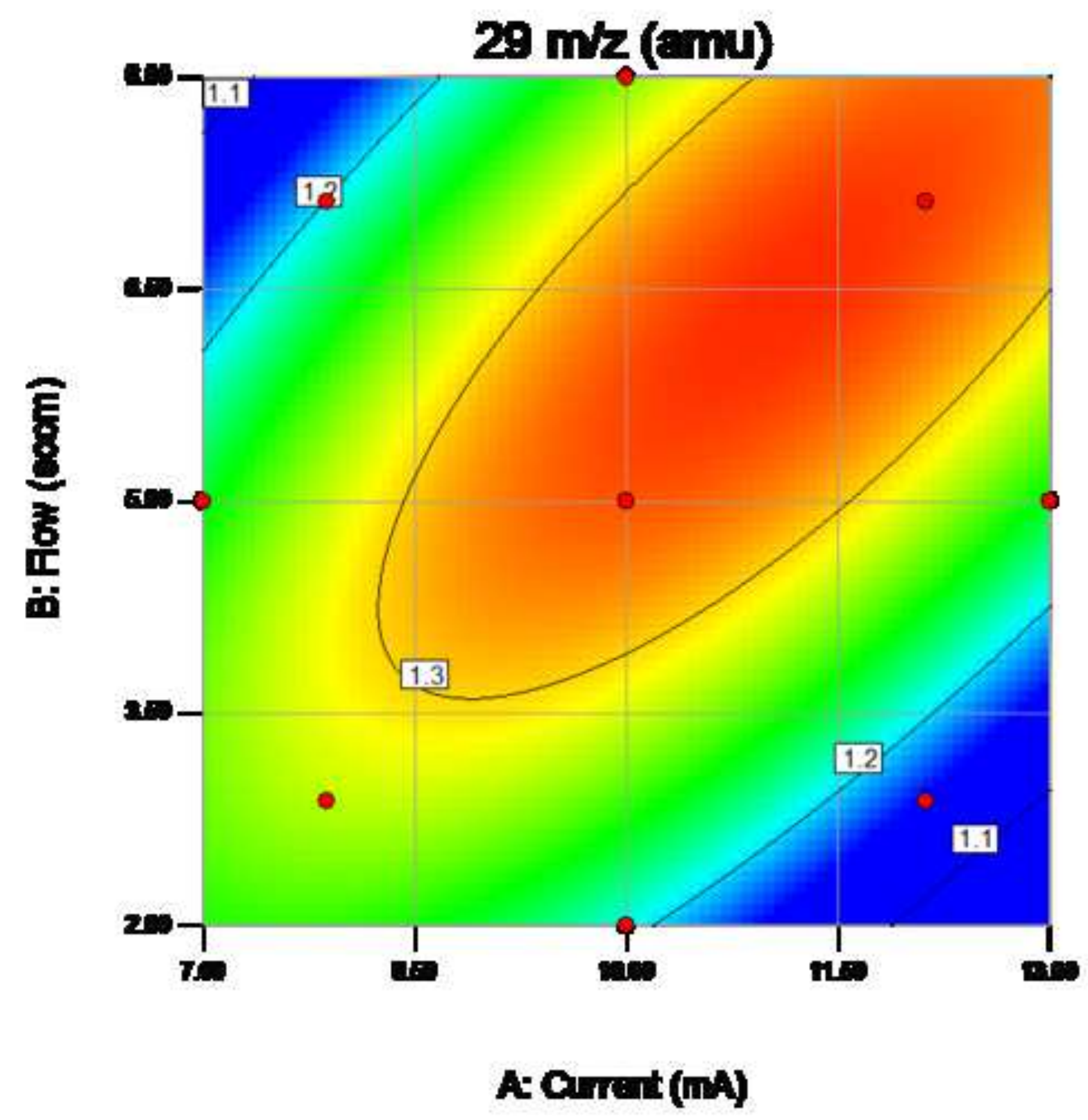

A: Curtent (mA) 
Table 1. The plasma treatment parameters of the 15 treated groups.

\begin{tabular}{llll}
\hline Run & $\begin{array}{l}\text { Factor 1 } \\
\text { Current } \\
(\mathrm{mA})\end{array}$ & $\begin{array}{l}\text { Factor 2 } \\
\text { Flow } \\
(\mathrm{sccm})\end{array}$ & $\begin{array}{l}\text { Factor 3 } \\
\text { Time } \\
(\mathrm{min})\end{array}$ \\
\hline 1 & 10 & 5 & 5 \\
2 & 10 & 5 & 9 \\
3 & 11.8 & 3.2 & 2.6 \\
4 & 8.2 & 6.8 & 2.6 \\
5 & 10 & 2 & 5 \\
6 & 11.8 & 6.8 & 7.4 \\
7 & 8.2 & 6.8 & 7.4 \\
8 & 8.2 & 3.2 & 7.4 \\
9 & 10 & 8 & 5 \\
10 & 13 & 5 & 5 \\
11 & 7 & 5 & 5 \\
12 & 11.8 & 3.2 & 7.4 \\
13 & 10 & 5 & 1 \\
14 & 8.2 & 3.2 & 2.6 \\
15 & 11.8 & 6.8 & 2.6 \\
\hline
\end{tabular}


Table 2. XPS analyses of ramie fibers.

\begin{tabular}{lllllllll}
\hline \multirow{2}{*}{ Group } & \multicolumn{3}{l}{$\begin{array}{l}\text { Chemical } \\
\text { Composition (at. \%) }\end{array}$} & $\begin{array}{l}\text { Atomic } \\
\text { Ratio }\end{array}$ & Relative percentage of C1s (at. \%) \\
\cline { 2 - 9 } & $\mathrm{C}$ & $\mathrm{O}$ & $\mathrm{N}$ & $\mathrm{O} / \mathrm{C}$ & $\mathrm{C}-\mathrm{C}$ & $\mathrm{C}-\mathrm{O}$ & $\mathrm{C}=\mathrm{O}$ & $\mathrm{O}=\mathrm{C}-\mathrm{O}$ \\
\hline Untreated & 67.4 & 32.6 & 0 & 0.48 & 40.7 & 44.0 & 11.3 & 4.0 \\
\hline DBD & 65.5 & 34.5 & 0 & 0.53 & 38.6 & 45.8 & 13.1 & 2.5 \\
\hline DBD + ethanol & 83.4 & 16.6 & 0 & 0.20 & 73.5 & 22.4 & 2.9 & 1.2 \\
\hline
\end{tabular}


Table 3. The ratio $r$ of ion fragment abundance during plasma treatment.

\begin{tabular}{llllll}
\hline Run & $\begin{array}{l}\text { Factor 1 } \\
\text { A: Current } \\
(\mathrm{mA})\end{array}$ & $\begin{array}{l}\text { Factor 2 } \\
\text { B: Flow } \\
(\mathrm{sccm})\end{array}$ & $\begin{array}{l}\text { Response 1 } \\
29 \mathrm{~m} / \mathrm{z} \\
(\mathrm{amu})\end{array}$ & $\begin{array}{l}\text { Response 2 } \\
45 \mathrm{~m} / \mathrm{z} \\
(\mathrm{amu})\end{array}$ & $\begin{array}{l}\text { Response 3 } \\
46 \mathrm{~m} / \mathrm{z} \\
(\mathrm{amu})\end{array}$ \\
\hline 1 & 12.1 & 2.9 & 1.161 & 0.617 & 0.591 \\
2 & 10 & 5 & 1.201 & 0.635 & 0.607 \\
3 & 10 & 2 & 1.223 & 0.930 & 0.856 \\
4 & 7.9 & 7.1 & 1.322 & 0.883 & 0.801 \\
5 & 12.1 & 7.1 & 1.336 & 0.856 & 0.752 \\
6 & 7 & 5 & 1.217 & 0.912 & 0.849 \\
7 & 10 & 8 & 1.252 & 0.841 & 0.825 \\
8 & 7.9 & 2.9 & 1.296 & 0.785 & 0.647 \\
9 & 13 & 5 & 1.245 & 0.760 & 0.703 \\
\hline
\end{tabular}

